\title{
Deep Disagreement and Informal Logic: No Cause for Alarm
}

\author{
ANDREW LUGG University of Ottawa
}

In a recent paper in this journal,[1] Robert Fogelin argues that "there are disagreements, sometimes on important issues, which by their nature, are not subject to rational resolution"'(p.7). Contrary to the view of many partisans of informal logic, he maintains that in certain cases (specifically, in cases of what he calls deep disagreement) argument is pointless and nonrational persuasion the only alternative. In his view, deep disagreement precludes "argumentative exchange" since "to the extent that the argumentative context becomes less normal, argument, to that extent, becomes impossible"'(p.4). Indeed, for Fogelin, "the language of argumentation, including the language of argumentative assessment, has its primary application in the context of normal or near normal argumentative

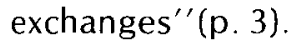

Fogelin explains the contrast between ordinary and deep disagreement in terms of whether or not the participants share sufficiently broad background of commitments to engage in genuine argument. Whereas in the normal course of events individuals agree concerning what is needed to settle the issues between them, in the case of deep disagreements, the required consensus about how to proceed is unavailable. Since "arguing, i.e., engaging in argumentative exchange, presupposes a background of shared commitments"' (p. 3), individuals who differ fundamentally are bound to talk past one another. As Fogelin puts the point, in the case of deep disagreement, "the language of argument may persist, but it becomes pointless since it makes an appeal to something that does not exist: a shared background of beliefs and preferences" (p. 5).

In arguing this view, Fogelin takes it for granted that individuals who share sufficient commitments to engage in genuine argument also share sufficient commitments to forge a mutually acceptable point of view. But presumably the interesting case is the one in which individuals are able to argue yet unable to settle their differences, i.e., the case in which there exists a framework for disagreement but not one for bringing about its resolution. It is not a strike against informal logic that it does not possess the resources for resolving the irresolvable, still less that the language of argument cannot always be applied. What makes disagreements interestingly deep is not that the parties to them talk at cross-purposes but rather that they differ even though they share a rich body of commitments (possibly including even views about what is required to settle the issues between them).[2]

Certainly, the examples that Fogelin gives of deep disagreement - the abortion and reverse discrimination debates - are cases in which the "language of argument" is entirely appropriate. True, the parties to these debates have had little success in convincing one another to change their views, but it can hardly be denied that they have been engaged in argument (some of it at an exceptionally high level). What makes these and similar cases interesting for proponents of informal logic is not that 
the parties fail to agree concerning the prerequisites for genuine argument but their agreement with respect to these prerequisites is insufficient to settle the issues that separate them. Indeed, it is plausibly argued that debates about abortion, reverse discrimination and the like are especially important precisely because they occur within extensive frameworks of shared beliefs and preferences.

In response to this view of deep disagreement (which I take to capture the spirit of Fogelin's position), it is tempting to argue that it is a requirement of rational argument that controversial assumptions be treated as conclusions to be argued for rather than as premises to be accepted. On this view, individuals involved in deep disagreements, no less than those involved in "normal argumentative exchanges", should always suspend judgement concerning the questions at issue and attempt to determine which if any of their views can be justified given the shared commitments underlying their arguments. Such a view, however, fails to take into account the depth of the resources available to those engaged in deep disagreement. As Fogelin observes, "when we inquire into the source of a deep disagreement, we do not simply find isolated propositions..., but instead a whole system of mutually supporting propositions (and paradigms, models, styles of acting and thinking)" (pp. 5-6).

Nonetheless, it is one thing to maintain that individuals may find themselves in the situation of being unable to resolve their differences on the basis of shared commitments, quite another to conclude that in such cases argument is pointless and nonrational persuasion unavoidable. Questioning the effectiveness of the strategy of reverting to neutral territory is not at all the same thing as questioning the possibility of rational discussion. Reason may not be sufficient to decide a particular issue here and now but it may still contribute significantly to its resolution later on. While it is undoubtedly true that deep disagreements cannot be immediately resolved by "normal criticism", it is not at all obvious that they can never be resolved this way, nor even that normal argumentative exchange can never have an effect.[3]

To put the point another way, individuals who disagree deeply may still be able to narrow the distance between themselves by dint of argument, debate; inquiry and research. The strategy of reverting to neutral ground is only one strategy among many. Individuals can also bring about a shift in one another's allegiances by demonstrating hidden strengths of their own views and by eliciting hidden weaknesses of alternative views. Furthermore, they may find themselves having to shift ground as a result of their discovering things wrong with the views that they accept and things right with the ones that they reject. What we would expect to find is what we in fact find-the development and defense of the various views under discussion along with the gradual formation of consensus.[4] Of course, there is no guarantee that agreement will always be achieved by argumentative exchange, but this is hardly a reason for not making an effort.

Consider the case of reverse discrimination. Like Fogelin, I see no way in which the clash of viewpoints concerning this issue can be satisfactorily resolved at present, yet I would also insist that it is possible and perhaps even $\mathrm{l} i$ kely that it will be resolvable in the future. Even granting that the debate reduces to a fundamental clash of views concerning the cogency of appeals to the rights of groups (as Fogelin plausibly argues), there remains the possibility of settling the issue one way or the other by mounting arguments that are neutral with regard to the question of group rights. The fact that quotas are inimical to fairness and justice unachievable without them may well be what has stymied the debate up to now, but this hardly precludes the two sides negotiating a position that they can live with at least temporarily. Indeed, it is not implausible to argue that recent debates concerning this issue have resulted in a noticeable shift towards such an "equilibrium position". 
What I am suggesting is that we take common viewpoints to be what individuals move towards rather than what they fall back to. Instead of thinking of shared belief as a "common court of appeal", we should think of it as a product of discussion, argument and debate. When we engage in argumentative exchange, our aim is not to determine what we and our opponents can agree on given the information that we share but to derive a common position, to figure out what we should believe, to ascertain the correct view of the matter. What we happen to agree on is important because it provides a starting point for discussion between us, not because it dictates what the outcome of our discussion should be. Except for the relatively trivial case of "normal exchange", differences of opinion are not resolved on the basis of shared assumptions; rather shared assumptions are obtained as a result of differences being resolved.

When thinking about debates among individuals, it is helpful to recall John Dewey's conception of deliberation as involving a "dramatic rehearsal" in imagination of competing possibilities.[5] In debate no less than in deliberation, ideas are disentangled, coordinated and systematized, reasons are marshalled, suspect assumptions are isolated, alternative proposals are reviewed, and conflicting demands are negotiated. Furthermore, the parties to disagreements find themselves having to modify, revise, supplement and renounce views when debating just as they find themselves being driven from point to point by the internal dynamics of their deliberations. The only difference between the two sorts of inquiry is that in debates the various approaches that individuals explore on their own are taken up and defended by others. Internal reflection gives way to external debate, and private discussion is transferred to the public arena.

It might be argued that were these observations spelled out in detail, they would be seen to presuppose a conception of public deliberation that is to all intents and purposes identical to Foge- lin's conception of normal argumentative exchange based on shared assumptions. But why think this? It is not being assumed that individuals genuinely engaged in debate can always force a decision one way or the other. Nor, more importantly, is it being claimed that they confine themselves to considerations that are as acceptable to their opponents as to themselves.[6] In fact, the more details we introduce concerning the criticisms that individuals urge in the course of discussions and the ways in which they rework their positions, the more reasonable the picture of their reasoning their way to a common position becomes. An account of the resolution of disagreements in terms of informal debates may well leave a lot unsaid, but it should not be dismissed as being vague, deceptive or merely metaphorical.

Furthermore, it would be inappropriate to complain that debates are rational only insofar as they conform to general logical principles. Logical considerations do certainly play an important role in debate (along with many other kinds of factual and conceptual considerations). But it is surely implausible to suppose that debates are governed by logical principles. For one thing, logic does not determine whether conclusions should be accepted or premises rejected; and for another, it provides no guidance concerning the appropriateness of continuing to defend a point of view, repudiating it or setting it aside pending further investigation. If a model of debate is needed, we would be well advised to stop thinking of it as being subject to rule and instead think of it as a capacity that we exercise to a greater or lesser degree and more or less well, i.e., as a practice on a par with speaking a language, riding a bicycle and painting a picture. [7]

These observations accord well with Fogelin's views about the inadequacy of traditional accounts of argument in terms of logical principles. I certainly do not mean to be understood as questioning his criticism of treatments of informal logic as second-rate formal logic (p. 1) or as countering his insistence on 
the fact that "an argument is produced by arguing", i.e., that it is "something that people do" as opposed to a "structure on propositions" (p. 2). Quite the opposite: my main contention is that these points need to be taken more seriously than informal logicians, Fogelin included, usually take them. As I see it, deep disagreement poses a serious problem only when the activity of deriving conclusions is "depsychologized" and reasoning is seen to be a matter of applying general logical principles. When we regard reasoning, thought, deliberation and the like as practices, we avoid the awkward assumption that argumentative exchanges must be always either normal (and hence rational) or nonrational (because abnormal). [8].

Thus, I find myself rejecting the dilemma with which Fogelin closes his paper. Were deep disagreements always rationally unresolvable, we would indeed be obliged either to own up and acknowledge the fact or to dissemble and attempt to keep it hidden from the general public. However, if what I have been arguing is correct, this difficulty need not concern us. For once we reject the assimilation of argument to "structures of propositions" , the resolvability of disagreement no longer stands and falls with the existence of shared procedures for its resolution and the propriety of persuasion no more poses a problem for disputes about fundamentals than it does for routine differences of opinion. It may well be true that deep disagreements pose formidable practical difficulties, but why think that they must also be impervious to reason and antithetical to resolution by rational argumentative exchange?

\section{Notes}

[1] R. Fogelin, "The Logic of Deep Disagreements", Informal Logic, VII. 1, pp. 1-8. All page references in the text are to this paper.

[2] Fogelin develops the thesis that argument fails in cases of deep disagreement with reference to Witt- genstein's remarks in On Certainty. This is helpful since it brings out the point that deep disagreements reflect fundamental differences of opinion. But it is also misleading since the kinds of disagreement of interest to Fogelin are far more prosaic than those of interest to Wittgenstein. In On Certainty, Wittgenstein is concerned with the status of claims (such as Moore's insistence that he has two hands) that it makes no sense to deny; he does not purport to be clarifying the status of claims that are open to reasonable doubt. In this regard, it should also be noted that Fogelin himself allows that "even with deep disagreement, people can argue well or badly" ( $p$. 7).

[3] Compare this with Fogelin's view that "it is characteristic of deep disagreements that they persist even when normal criticisms have been answered" (p. 5).

[4] For examples of converging points of view, see W. Whewell, "On the Transformation of Hypotheses in the History of Science" in R.E. Butts (ed.), William Whewell's Theory of Scientific Method, University of Pittsburgh Press, Pittsburgh, 1968. One might dispute Whewell's history but he is surely right to suppose that debates may conclude with the views under discussion having "passed into one another" (p. 261).

[5] J. Dewey, Human Nature and Conduct, Modern Library, New York, 1930 , p. 190 . See also the discussion of deliberation in my "The Process of Discovery", Philosophy of Science, 52 (1985), pp. 207-220, especially section IV.

[6] Here it is important to note that the strategy of reverting to common ground clashes with the methodological principle of total information, i.e., the obligation that we have to take into account all the information that we deem to be rele- 
vant to the issues at hand. It is a mistake to suppose, as is often done, that standing one's ground is tantamount to begging the question. One commits this fallacy when one responds to criticism by rehearsing considerations that have already been challenged; one does not commit it when one introduces new reasons (even though these may be subsequently challenged).

[7] I take this suggestion to be in closer accord with Wittgenstein's later philosophy than the view that Fogelin elicits from On Certainty. In my view, Wittgenstein's point is not that rational procedures are relative to "framework principles" (which is what Fogelin's quota- tions from On Certainty seem to suggest) but rather-to put it very roughly - that intellection is better thought of in terms of skills than in terms or rules.

[8] Might not the name "informal logic" be part of the problem? If "logic" were reserved for the theory of validity and "reasoning" used to cover the kinds of issues normally discussed under the rubric of informal logic, the idea of "principles of argument" would probably seem far less attractive.

Prof. Andrew Lugg, Department of Philosophy, University of Ottawa, 65 Hastey, Ottawa, Ontario, K1N 6N5 